\title{
El velamiento de la evidencia en el Simbolismo y el Surrealismo belgas
}

\author{
The veiling of evidence \\ in Belgian Simbolism and Surrealism
}

\author{
MARTINE RENOUPREZ \\ Universidad de Cádiz (España)
}

Recibido: 6-XII-2015 Aceptado: 14-XII-2015

\section{RESUMEN}

La sociología de la literatura da explicación de las condiciones de existencia de lo literario en Bélgica y de su rivalidad inevitable con la institución francesa. Es posible señalar, entre estos dos campos literarios, vínculos diacrónicos de connivencia, con particular relieve entre el Simbolismo y el Surrealismo desarrollado en ambos países: comparten el rechazo de las constricciones que tiranizan al individuo y la defensa de la escritura como vía de liberación hacia una vida más plena. A la vez, la sociología de lo literario nos permite advertir las diferencias, cruciales, entre el Surrealismo de André Breton y el de Paul Nougé.

\section{PALABRAS CLAVE}

MAETERLINCK, NOUGÉ, SIMBOLISMO BELGA, SURREALISMO BELGA

\section{ABSTRACT}

The sociology of literature explains the conditions for the existence of literature in Belgium and its inevitable rivalry with the French institution. Between these two literary fields, we could remark the diachronic similarities, especially between Symbolism and Surrealism: their aversion to those constraints which imprison the individual, those against writing traces out of the path of a possible liberation towards a fuller life. The sociology also highlights the differences, which are crucial, between the Surrealism of André Breton and that of Paul Nougé.

\section{KEYWORDS}


MAETERLINCK, NOUGÉ, BELGIAN SIMBOLISM, BELGIAN SURREALISM

\section{INTRODUCCIÓN}

PARA ENTENDER EL COMPORTAMIENTO de la literatura en Bélgica, y en particular de los movimientos artísticos simbolistas y surrealistas, es necesario precisar la naturaleza de las interacciones literarias entre Francia y Bélgica. A partir del siglo XIX, el campo institucional de la literatura se desarrolla en París (Dubois 2005). Se asiste entonces a encendidas luchas de poder: los movimientos estéticos se alternan, oponiendo forma y contenido, a través de estrategias para ganar puestos clave en las instancias de legitimación (revistas, editoriales, Academias, etc.) que les otorgarán un reconocimiento simbólico. Lo que está en juego es importante y los clanes literarios tienen reglas estrictas que no admiten desviaciones y dependen de la figura tutelar. Stéphane Mallarmé fue, en este sentido, el modelo de la élite intelectual con su enseñanza hermética, accesible sólo a los iniciados. Representará para el Simbolismo lo que André Breton fue para el Surrealismo cuarenta años más tarde.

Bélgica, que acaba de obtener su independencia en 1830, busca también dotarse de una literatura nacional, propia e independiente. Este territorio une de manera artificial dos culturas distintas, la primera en el Norte, flamenca, y la segunda en el Sur, francófona. Lo que animó a estas dos regiones a unirse fue un asunto religioso: después de la caída de Napoleón en 1815 y de la anexión de Holanda, la región flamenca, católica y conservadora, no podía quedarse bajo la dependencia de una Holanda protestante y de tendencia calvinista. Quedaba la delicada cuestión lingüística entre el Norte y el Sur, pero esta cuestión no se planteó en el momento de la fundación del país ya que la burguesía de las dos regiones hablaba francés, el idioma de prestigio de su clase y de la nobleza en general en la Europa de aquella época. Más tarde la reivindicación del pueblo flamenco, de su derecho al reconocimiento de su propia lengua y de su cultura, desembocará en el proceso de federalización del país. Entretanto, se dota de un lema cuya meta es unir ambas comunidades: «La unión hace la fuerza» y de un mito cultural, la idea de un "Alma belga», específica de esta nación nacida en el cruce de las culturas germánica y latina.

Pero cabe entender que el campo literario parisino, con sus instancias de legitimación, es el único habilitado para arbitrar los asuntos de lengua francesa; es el que otorga el poder simbólico a un autor o un movimiento literario, a partir de reglas estrictas de selección, implícitas y establecidas para cada periodo histórico. Una literatura en francés fuera del Hexágono no podrá consolidarse sin su consentimiento. Por estas razones, la constitución de un campo literario autónomo, en lengua francesa, en Bélgica, no podía ignorar y pasar por alto el 
reconocimiento del campo literario parisino. ${ }^{1}$ Un conjunto de circunstancias iba a favorecer esta estructuración alrededor de 1880 y hacer crecer el valor del Simbolismo belga hasta su máximo reconocimiento con el premio Nobel de literatura otorgado en 1911 a Maurice Maeterlinck.

\section{CONSTITUCIÓN DE UN CAMPO LITERARIO ALREDEDOR DE 1880 EN BÉLGICA}

Condiciones desfavorables para los editores en Francia, como la censura y la incoación de procedimientos legales en contra de los que mostraban demasiada libertad -sea política o artística- les empujará a expatriarse a Bélgica e instalarse en Bruselas, la ciudad preferida de los proscritos desde 1815. Auguste Poulet-Malassis publicará ahí Les Épaves de Baudelaire en 1866, así como libros eróticos ilustrados por Félicien Rops; Albert Lacroix edita Les Misérables de Victor Hugo, en 1862, y Les Chants de Maldoror de Isidore Ducasse, en 1869, pero también toda la obra de Proudhon. Fue asimismo el propietario del conjunto de los Rougon-Macquart de Émile Zola (Mollier 1997, 58). Henry Kistemaeckers, afectado por la represión en contra de los partidarios de la Comuna de 1871, se instala también en Bruselas para publicar a los naturalistas, tanto belgas como franceses. Añadamos también a Edmond Deman, editor de los Simbolistas que publicará sólo unas cincuenta obras en ediciones lujosas, entre otras Les Poésies de Mallarmé en 1899 (Baudet 1986; Durand y Winkin 1996). La «autonomía» de lo literario en Bélgica, en aquella época, implica diversas consecuencias. En primer lugar, que las reglas estrictas del campo literario parisino se diluyen fuera de las fronteras del Hexágono. Al contrario de Francia, donde cada escuela privilegia un género literario, movimientos y géneros comienzan a desarrollar fuera diversas formas híbridas. Así, el libro de poemas Rimes de Joie de Théodore Hannon se afilia a la vez al Naturalismo y al artificio propio de Baudelaire o de L'École du Parnasse. El Simbolismo, estrictamente poético en Francia, abraza en Bélgica todos los géneros, desde la novela hasta la poesía y el teatro. Las distintas revistas que animan la vida literaria se configuran de la misma manera: L'Artiste (1875-1880) obedece al lema «Naturalisme, Modernité», guiño al Peintre de la vie moderne de Baudelaire, pero no manifiesta ninguna propensión a la exclusión, sino más bien a la inclusión de cualquier novedad artística, siendo el único enemigo común de la burguesía. La Jeune Belgique (1881-1897) acoge todas las tendencias bajo un eslogan que denota a la vez una voluntad de autonomía y un cierto nacionalismo: «Soyons-nous»; sin embargo, hay que seguir lo que produce París, sin generar conflictos y ocupando el conjunto del campo literario. La

1 Esta cuestión ha sido ampliamente estudiada y detallada por Jean-Marie Klinkenberg a partir de este primer artículo sobre el tema: Klinkenberg 1981. 
revista asimila pues tendencias naturalistas (Camille Lemonnier et Georges Eekhoud), parnasianas (Albert Giraud) y simbolistas (Maurice Maeterlinck, Charles Van Lerberghe o Emile Verhaeren), hasta la aparición de disensiones con la publicación rival L’Art moderne (1881-1914). La primera se cierra sobre la tendencia parnasiana del culto de la belleza, hacia 1883, mientras ésta se centra en la preocupación social del arte. El tercer eje, en cuanto a revistas en el campo literario de los años 1880, tiene en su centro La Wallonie (1886-1892), creada por Albert Mockel, la cual se aleja de las funciones utilitarias del arte y gana para sí a destacados colaboradores de las otras dos revistas, como Verhaeren, Rodenbach, Georges Khnopff -el hermano del pintor- o Van Lerberghe. Aprovecha la desaparición de la revista de los simbolistas franceses, Écrits pour l'Art, para recibir su colaboración, eliminando los conflictos internos y las disensiones de la esfera parisina. ${ }^{2}$

Otra consecuencia de esta autonomía de lo literario es la búsqueda inevitable del aval de los escritores franceses. Por un lado, la presencia de editores de prestigio en Bruselas incita a los autores famosos - en realidad poco podían elegir-a publicar en Bélgica, lo que -como vasos comunicantes-confería un reconocimiento a los autores belgas que publicaban en las mismas editoriales. La colaboración de los escritores franceses en las revistas y editoriales belgas tuvo como consecuencia que la literatura producida allí fuera enteramente reconocida por París, lo que conllevó numerosos intercambios. La tercera consecuencia de esta autonomía de lo literario -y no la menor- es que uno de los criterios de las instancias de legitimación parisinas para otorgar valor a alguna producción cultural producida fuera del Hexágono consiste en reconocer en ella una alteridad definida por sus rasgos propios. Por esta razón, la literatura belga del siglo XIX fue calificada de «nórdica» y los escritores acentuaron los rasgos específicos de la cultura flamenca, una característica todavía visible hoy en algunas producciones, como las canciones de Jacques Brel o de Arno. ${ }^{3}$

\section{EL VELAMIENTO DE LA EVIDENCIA EN LOS SIMBOLISTAS BELGAS}

Dos características van a marcar este movimiento; por una parte, la importancia concedida al símbolo, bajo la égida de Mallarmé, y, por otra parte, la inscripción de las fuentes nórdicas que atraviesan las producciones literarias y artísticas reconocidas en su alteridad.

«Estética idealista fundada en el principio que la realidad no puede ser descrita directamente a través de un lenguaje denotativo, el símbolo confiere a la palabra un valor sugestivo que suplanta su función referencial» (Biron 1994,

2 En lo que concierne a las revistas, vid. Aron y Soucy 1993.

3 Las consecuencias de las interacciones entre los campos literarios franceses y belgas han sido estudiados por Biron (1994). 
127). Como lo indica su nombre, el símbolo tiene como meta volver a crear la unidad que ha sido dividida, sublimar la dualidad en la totalidad. Se enlaza -en última instancia- con el mito de la unidad original, conteniendo las dos caras contradictorias y complementarias de esta totalidad. El símbolo, sea la palabra en la escritura o la imagen en la pintura, solo reenvía en primera instancia al objeto que designa; más allá de este primer grado, de apariencia concreta, otras interpretaciones son solicitadas hasta su sentido hierofánico. El símbolo lleva, más allá de lo visible, los signos de lo invisible. «Implica o exige, en el fondo, una metafísica» (Brunetière 1894, t. 2, 253, citado por Gorceix 1998, 65).

Albert Mockel, director de La Wallonie y teórico del movimiento, tomó la precaución de distinguir el símbolo de la alegoría. Ambos expresan una idea abstracta a partir de una imagen concreta. Sin embargo, para él. «la alegoría [es] la obra del espíritu humano en la cual la analogía es artificial y extrínseca», mientras que en «el símbolo la analogía aparece natural e intrínseca. La alegoría sería la representación explicita o analítica, mediante una imagen, de una idea abstracta preconcebida; sería la representación convenida - y por tanto explícita- de esta idea [...]. Al contrario, el símbolo supone la búsqueda intuitiva de distintos elementos ideales dispersos en las Formas» (Mockel 1998, 606-607). La búsqueda de los simbolistas no se limita a las representaciones alegóricas de ideas abstractas tal como la Justicia por Minerva. No se trata tampoco de un emblema. El símbolo lleva a pensar: las formas propuestas deben suscitar en el lector una investigación intuitiva hacia el sentido entrevisto por el artista. ${ }^{4}$ Está claro que para los Simbolistas el universo es un conjunto de formas y todas convergen en el la unidad, sin que ésta sea nunca nombrada, ni se encarne en ninguna revelación dogmática: «En la naturaleza, cualquier representación es simbólica, porque el alma se manifiesta en ella y, como quisiera decirlo, todas las cosas convergen hacia una meta única. Las Formas son el verbo del Ser que escribió con mundos su pensamiento o a sí mismo» (Mockel 1998, 607). Juntar las formas debe pues suscitar la armonía que se encuentra en uno mismo y que acerque lo más posible a cada uno a la harmonía de la totalidad. La idea de Belleza y de infinito que se observa en la naturaleza y que se intenta volver a crear nos acerca a la vez al ideal y a nosotros mismos. ${ }^{5}$ La obra, por la grandeza a la que aspira, nos realiza haciéndonos crecer. No se restringe a una idea ni a una imagen fija, practica el arte de la sugestión; velada, se dirige a la intuición que busca su sentido. La obra debe suscitar un «estremecimiento

4 «Pero el Poeta debe buscar menos concluir que dar a pensar, de tal modo que el lector, colaborando con lo que él adivina, acaba en él mismo las palabras escritas» (Mockel 1998, 612).

5 «Buscando en las cosas la imagen de lo infinito, forzando a las cosas a expresar lo infinito, el Poeta descubré el signo en él mismo. El alma entrevé su Objetivo, el alma se aproxima a Dios, el ser futuro, término supremo de su ritmo [...]. C'est la raison d'être de l'œuvre d'art» (Mockel 1998, 612). 
ilimitado» y «sugerir lo infinito». Maurice Maeterlinck precisa esta distinción establecida por Mockel. Para él, la alegoría y el emblema serían de alguna manera «símbolos a priori; el símbolo controlado; a partir de abstracciones intenta vestir de humanidad estas abstracciones» (Maeterlinck 1891, 150). Mientras que «la otra especie de símbolos sería más bien inconsciente, tendría lugar sin que el poeta lo sepa, muy a menudo a pesar de él, e iría, casi siempre, mucho más allá de su pensamiento» (Maeterlinck 1891, 150). Inspirado por un sentido que lo supera y se revela a posteriori, el artista trabaja con las fuerzas del universo. Maeterlinck lo compara con la postura del carpintero de Emerson que desbasta una viga en el suelo mientras la fuerza de gravitación multiplica cada uno de sus movimientos. ${ }^{6}$ Las potencias que atraviesan el ser proceden tanto del exterior -la energía cósmica- como del interior el inconsciente, lo que hizo decir a Antonin Artaud que «Maeterlinck fue el primero en introducir en la literatura la riqueza múltiple de lo inconsciente» (Artaud 1923), mucho antes que los surrealistas.

Los simbolistas belgas se distinguen por su interés hacia la filosofía de la traidicón neoplatónica, desde Plotino a Paracelso, y todas las místicas. Maeterlinck fue el traductor de L'Ornement des noces spirituelles de Ruysbroeck l'Admirable (1293-1381), uno de los maestros de los Rosacruces (Delay 2000, Correspondance, 6, 17), la sociedad esotérica iniciática para la cual Joséphin Péladan había creado en 1890 la Rose-Croix esthétique, que animaba Salones en los cuales participaban los pintores simbolistas belgas Jean Delville y Fernand Khnopff. No olvidemos que Debussy, autor de la transformación en ópera de la obra de teatro de Maeterlinck Pelléas et Mélisande, también era rosacruz. El propio Maeterlinck fue gran lector de Louis-Claude de Saint-Martin (1743-1803) y de Joachim Martinez de Pasqually (1727-1779), creadores de la Orden Martinista, y también de Emmanuel Swedenborg (1688-1772) y de Jacob Böhme (1575-1624), teósofos y místicos sueco y alemán (Gorceix 1997, 171-180).

Su interés por el ocultismo, la «res occultae», procede de la conciencia aguda del misterio de la existencia del universo y de los límites del racionalismo para entenderlo. Este racionalismo que había dividido, creado la dualidad para categorizar el mundo a partir de los principios de identidad, no contradicción y tercio excluido, había cimentado las bases de la filosofía y permitido el desarrollo de las ciencias pero también había arrojado al ser humano en el desarraigo, la separación del universo, de sus semejantes y de sí mismo. Este sentimiento

6 «Una imagen puede desviar mi pensamiento; si esta imagen es exacta y es debida a una vida orgánica, ella obedece a las leyes del Universo de modo más estricto que mi pensamiento; y es por esto por lo que estoy convencido de que ella tendrá casi siempre razón contra mi pobre pensamiento abstracto; si yo la escucho, es el universo y el orden eterno de las cosas los que piensan en mi lugar» (Maeterlinck 1891, 151). 
de soledad y de abandono llamaba a la reconciliación consigo mismo y el gran todo. Son las fuentes del Romanticismo alemán -demasiado poco entendidas en una Francia empapada de racionalismo y alejada de Alemania después de la guerra de 1870 y en la cual dominaba el Realismo y después el Naturalismo en las artes - las que alimentaron la imaginación de los simbolistas, en particular, los belgas. Su inconsciente literario está impregnado por las reflexiones y los preceptos formulados por los dos hermanos Schlegel, por Schelling y Novalis -Maeterlinck fue el traductor de los Fragments y de Disciples à Saïs- que fundaron el Romanticismo a partir de un lugar, Iéna, y de una revista, L'Athenaeum, entre 1798 y 1800 . Su idea de reconciliación hacia la unidad se encontraba ya en germen en «el más antiguo programa del idealismo alemán» formulado por Hegel, Hölderlin y Schelling, dos años antes, en 1796, que promovía la unión de los elementos contrarios, empezando por la poesía y la filosofía, debiendo la razón aliarse con la sensación y la intuición. La poesía volvía así a ser lo que era antes, la educadora de la humanidad en un intento de reunificar lo que había sido separado durante siglos. ${ }^{7}$

La unidad original perdida estuvo también en el crisol de las búsquedas místicas y del ocultismo. En virtud de la relación analógica, el proceso mismo desencadenado por el símbolo, lo desconocido puede ser conocido y el misterio acercado. En este sistema de pensamiento, las correspondencias son una evidencia -entre el exterior y el interior, lo alto y lo bajo, la luz brillando en las tinieblas-como lo sintetiza la Tabla de esmeralda de Hermès Trismégisto. Lo que fascina a Maeterlinck, es que los místicos viven esta unidad que él sólo logra entrever. Fuera del razonamiento y de la tradición filosófica, Ruysbroeck, un aldeano iletrado que vivía en «su cabaña de Groenendael, en medio del bosque de Soignes» (Maeterlinck 2008, 68) está «determinado a pensar sólo en lo impensable» (Maeterlinck 2008, 63). Para hacer entender lo que percibe el místico, Maeterlinck convoca, por una parte, a Porfirio, quien indica, alejándose de la objetividad, que «lo semejante sólo se conoce por lo semejante, y que la condición de cualquier conocimiento implica que el sujeto se vuelva semejante al objeto» (Porfirio citado en Maeterlinck 2008, 65), y también a Plotino, su maestro: «Hay que configurar el órgano de la visión análogo y semejante al objeto que debe contemplar. Jamás el ojo hubiera percibido el sol, si no hubiera primero tomado la forma del sol; de la misma manera el alma no podría ver la belleza si primero no se volvía ella misma bella» (Plotino, citado en Maeterlinck 2008 , 74). Por otro lado, el punto de disolución de toda contradicción, punto de conocimiento de la unidad y por lo tanto de lo absoluto, está sugerido en

7 «Se trata de terminar con la separación y la división constitutivas de la historia; se trata de construir, de producir esto mismo que en el origen de la historia se pensaba como una «edad de oro» perdida y nunca más acesible» (Lacoue-Labarthe y Nancy 1978, 20). 
el texto de Maeterlinck por metáforas en las cuales los elementos opuestos se juntan: «Estamos aquí, de repente, en los extremos del pensamiento humano y mucho más allá del círculo polar del espíritu. Hace un frío extremo; una oscuridad extremada, y sin embargo, no encontraréis otra cosa que llamas y luz» (Maeterlinck 2008, 65); hasta llegar al oxímoron: «el sol de medianoche» (Maeterlinck 2008, 66). Plotino había ya indicado que ni el razonamiento ni la imaginación permitían alcanzar el conocimiento de lo absoluto, siendo la única vía la espera en la contemplación.

Considerando, sin embargo, a estos neo-platónicos demasiado cercanos a la dialéctica, Maeterlinck se vuelve, para comprender a Ruysbroeck, hacia el pensamiento intuitivo asiático, al afirmar que «cuando la inteligencia cierra el ojo a los demás objetos, cuando se concentra sobre sí misma, no viendo nada, no ve una luz ajena que brilla en formas ajenas sino su propia luz que, de repente, irradia interiormente con pura claridad» (Ruysbroeck, citado en Maeterlink 2008, 71). Aquella conciencia relacionada con el despertar del alma es específica, según Maeterlinck, de algunas épocas privilegiadas en un plano espiritual, como lo fueron el antiguo Egipto y la India, mientras que ni Grecia ni Roma, portadoras de inteligencia y de belleza, conocieron estos momentos excepcionales en los cuales «la humanidad estuvo a punto de sublevar un poco la pesada carga de la materia» (Maeterlinck 2008, 27). Las potencias ocultas que se revelan en este fin de siglo: el magnetismo, la telepatía, la levitación, la irradiación de la materia anuncian una época «en la cual nuestras almas se percibirán sin el intermediario de nuestros sentidos» (Maeterlinck 2008, 27). Parecen ya acercarse instintivamente unas a otras en un entendimiento sensitivo, más allá de los signos y de las palabras, que une más profundamente a los seres humanos en el amor, la ternura y la fraternidad: «Los hombres son más cercanos a sí mismos y más cercanos a sus hermanos; se miran y se aman más gravemente y más íntimamente. Comprenden más tiernamente y más profundamente al niño, a la mujer, a los animales, las plantas y las cosas» (Maeterlinck 2008, 27). En este círculo místico, las palabras se hacen superfluas, todo se juega alrededor de la simple presencia y se juzga en función de lo invisible.

Hemos mostrado, por una parte, que el símbolo tiene como meta lo invisible; iniciático, sugiere al lector o al espectador el trazado de una inteligibilidad por sí misma misteriosa y desconocida del propio creador. Por otra parte, es evidente que las fuentes de inspiración de los simbolistas proceden del Romanticismo alemán y de las místicas de origen germánico. Más concretamente, la influencia nórdica marcará directamente los temas de las obras producidas: a través de las ciudades y de los paisajes flamencos, con el resurgimiento de los mitos célticos, en particular las leyendas de las hadas acuáticas: Ondine, Morgane, Mélusine, etc. En la pintura, cabe notar la influencia determinante de los prerrafaelitas, entre otros Edward Burne-Jones, lo que no excluye otras 
influencias determinantes fuera de la Europa nórdica, tales como el Oriente, en particular el Japonesismo.

\section{El VELAMIENTO DE LA EVIDENCIA EN LOS SURREALISTAS BELGAS}

Sólo hay un paso entre la confesión de Maeterlinck como poeta, hecha en $1890,{ }^{8}$ y los núcleos de interés del Surrealismo defendidos por André Breton. Veamos lo que el simbolista nos dice sobre sus preocupaciones esenciales, que parecen ya contener en germen lo que se propone en el Primer Manifiesto del Surrealismo, de 1924: la idea de un apresamiento del ser en sus moldes, estructuras convenidas que son un fraude, un engaño y sólo pueden decepcionar frente a la verdadera vida; la atracción hacia las luces del inconsciente, lo que se desvela en el centro de los sueños, lo que queda no formulado, instintivo, del orden de los presentimientos, de lo inexplicado, de lo queda al límite de lo controlable, es decir lo que es susceptible de traspasar la razón, con una atracción por la locura; el mundo de la infancia también está evocado, para volver a encontrarlo en su dimensión a la vez espiritual y a través de sus miedos irreprensibles. Hay que añadir a esto la fascinación de André Breton por el ocultismo, cuando vuelve a formular para sí mismo los preceptos de la Tabla de esmeralda en su famosa declaración: «Todo induce a creer que hay un cierto punto del espíritu donde la vida y la muerte, lo real y lo imaginario, el pasado y el futuro, lo comunicable y lo incomunicable, cesan de ser percibidos de una manera contradictoria. En vano se le intentaría buscar a la actividad surrealista otro fin que la expectativa de determinación de ese punto» (Breton 1985, 72-73).

Alrededor de los años veinte André Breton provoca tensiones en el campo literario parisino, frente a los responsables de la N.R.F. que ocupan puestos de

8 «Me siento atraído ante todo por los gestos inconscientes del ser, que recorren con sus manos luminosas las posiciones artificiales en las que estamos encerrados. Querría estudiar todo lo que queda sin formular en una existencia, todo lo que carece de expresión en la muerte o en la vida, todo lo que busca una voz en un corazón. Querría volcarme sobre el instinto, en su sentido luminoso, sobre los presentimientos, sobre las facultades y nociones inexplicadas, descuidadas o apagadas, sobre los motivos irracionales, sobre las maravillas de la muerte, sobre los misterios del sueño, a pesar de la influencia demasiado poderosa de los recuerdos diurnos; nos es dado entrever, en ocasiones, una luz del ser enigmático, real y primitivo; sobre todas las potencias desconocidas de nuestra alma; sobre todos los momentos en los que el hombre escapa de su propia vigilancia; sobre los secretos de la infancia, tan extrañamente espiritual, con su creencia en lo sobrenatural y tan inquietante con sus sueños de terror espontáneo, ¡como si realmente viniéramos de una fuente de miedo! Yo querría acechar de este modo, pacientemente, las llamas del ser original, a través de todas las grietas de este tenebroso sistema de engaños y decepciones en medio de los cuales estamos condenados a morir» (Maeterlinck citado en Aron 1997, 458). 
poder en las instancias de legitimación. El Surrealismo se enfrentará a grupos literarios en potencia, tanto en sus ramificaciones internacionales -como los surrealistas belgas - como a otras vanguardias, en particular los partidarios del arte abstracto que lo atacarán frontalmente.

Frente al aura del jefe del movimiento y a sus preceptos claramente definidos a través de los distintos Manifiestos, los activistas del Surrealismo belga de Bruselas ${ }^{9}$ tuvieron que marcar su diferencia, quizás por una estrategia indirecta de reconocimiento. Los puntos de discordancia son numerosos sin que Breton nunca haya realmente evaluado el alcance de estas desemejanzas. El primer punto consiste en el rechazo de aparecer como un movimiento literario y de realizar una obra; Paul Nougé (Biron 1991, 53-70; Michel 2011, 113-157), personalidad faro entre los surrealistas de Bruselas, se oponía «con la mayor violencia a cualquier tipo de movimiento [...]. Nunca ha querido colaborar» (Mariën 1997, 16). Rechaza también cualquier publicación. ${ }^{10}$ Vanguardista convencido, su estrategia consiste en un ataque relámpago, circunstancial, con folletos, un soporte ligero, una carta -numerada y de color- enviada a una persona-blanco, generalmente una figura a la vista en el campo artístico o literario francés ${ }^{11}$ para criticar de manera insidiosa su práctica literaria. Se trata de un planteamiento de desestabilización de lo adquirido, de las certidumbres, de las convenciones. Los 22 folletos, enviados entre el 22 de noviembre de 1924 y el 20 de junio de 1925, se hacen bajo el nombre de Correspondance. ${ }^{12}$ Inquietos, Aragon y Breton irán a Bélgica para encontrarse con sus colegas de Bruselas. Coincidirán en cuanto al «rechazo de la estética y del arte tradicionales» (Mariën 1997, 14) y en lo relativo a las cuestiones políticas generales, firmando juntos un libelo en contra de la guerra de Marruecos ${ }^{13}$ : «Los Belgas firman pues, pero Nougé, de inmediato, hace aparecer un libelo en el cual toma

9 Se trata del grupo «Correspondance», de 1924, compuesto por Paul Nougé, Camille Goemans y Marcel Lecomte (enseguida excluido), a los cuales se unirán, en 1926, E.L.T. Mesens, René Magritte y Gérard Van Bruaene, dueño de La Feuille en papier doré, un cafetín en el cual se reunía el grupo, así como André Souris y Hooreman, músicos.

10 Paul Nougé escribe dos prefacios de catálogos en 1943 en los que precisa sus posturas en relación con el Surrealismo. Marcel Mariën agrupará sus manuscritos para publicarlos en una revista que crea, Les Lèvres nues, después del rechazo de su obra por parte de Gallimard (Mariën 1997, 28 et 47).

11 Fueron destinatarios de estas cartas «autoridades» como Paul Eluard, Philippe Soupault, Jean Paulhan, Marcel Proust, Pierre Drieu La Rochelle, André Lhote, Jean Cassou, Louis Aragon, Albert Saugère, Valéry Larbaud, Pierre Morhange, André Breton, Joseph Delteil, Marcel Arland, André Gide o Roger Martin du Gard.

12 Reeditados con un prefacio de Paul Aron (1993).

13 El grupo de Bruselas firmará bajo el nombre de «Correspondance» (Aron 1993, 1). 
distancia frente al mismo manifiesto» (Mariën 1997, 42-44). Porque Nougé se sitúa donde uno no lo espera.

En segundo lugar, los mecanismos del inconsciente, tan apreciados por los surrealistas bretonianos, fuente de creación a partir de lapsus, de la escritura automática y de la exploración de los sueños, son concebidos por Nougé como una invención. Se aleja de cualquier idea relativa a una interioridad, de la mente observada como una profundidad a sondear, de una extensión a explorar, para concebirlo, al contrario, como una construcción por emprender. ${ }^{14}$ Las nociones de verdad y de sinceridad, percibidas normalmente como valores en la comunicación, ya no están al orden del día en esta perspectiva (Nougé 1980, 90-91). Por el contrario, importa juntar unos medios razonados que permitirán inventar esta mente: «Nos ayudábamos a inventar sobre lo real dos o tres ideas eficaces» (Nougé 1980, 55). Se trata pues de una operación consciente, previsible, de una experimentación a partir del lenguaje para valorar sus posibilidades de impacto. No olvidemos que Nougé era un científico, bioquímico de formación, y aplica el planteamiento científico experimental, racionalizado, a la literatura -así lo recuerda en sus «Notas sobre la poesía»- para producir una «poesía de la experiencia» (Nougé 1980, 165), es decir una poesía que produce cierto efecto sobre el lector independientemente de cualquier pretensión de verosimilitud. Nougé considera el lenguaje como «un objeto adecuado para provocar, sobre quien lo recibe, ciertos estados, pensamientos o ciertas ideas, y lo usa como un objeto modificable, a la manera de un objeto material (mediante agregaciones, supresiones, interpolaciones, flexiones, etc.), con el fin de producir un cierto efecto previsto, presentido -o simplemente considerado imprevisible» (Nougé 1980, 167-168). Su práctica del lenguaje consiste entre otras cosas en desviar los clichés del lenguaje - proverbios, sentencias, expresiones fijas, locuciones, etc.- por medio de una intervención mínima en la ruptura de la espera fonética, semántica o sintáctica, como en el ejemplo siguiente, donde el sustantivo «doigts» se sustituye a la palabra «yeux» en la expresión común: «Je te regarde de tous mes doigts» (Nougé 1981, 140). Estos procedimientos han sido ampliamente estudiados y comentados (Michel 1997, 201-233) y pueden aplicarse a la interpretación de los cuadros de René Magritte. Si las obras de Max Ernst o Salvador Dalí salen de un sueño, las imágenes construidas por Magritte obedecen a operaciones procedentes del cálculo, del trabajo consciente del sabotaje de las pequeñas costumbres del lenguaje y de la visión. Independientemente de las numerosas exegesis producidas sobre los cuadros de Magritte, volvamos a las observaciones de Paul Nougé para entenderlas.

14 «[...] todo cambia si, abandonando esta peligrosa voluntad de descubrir el espíritu, nos proponemos ayudar a su invención, habiendo admitido que no hay existencia espiritual independiente de la afirmación que nosotros vayamos a hacer» (Nougé 1980, 59). 
Como en la escritura poética, no se trata ni de expresar un sentimiento ni de representar un espectáculo que se situaría fuera de sí mismo, sino de proceder a la invención de un universo alejando «cada vez más los límites de lo posible», de crear ocasiones, circunstancias que dan al objeto inventado «la mayor potencia sobre "el-universo-de-todas-las-costumbres"» (Nougé 1980, 220).

Esta potencia consistiría en la creación de nuevas sensaciones, de nuevos efectos para abrirnos a lo desconocido, ampliar el panorama de nuestros conocimientos y modificar nuestras relaciones con el mundo. Esta surrealidad buscada se crea aquí a partir de una surracionalidad (vid. Puelles Romero 2007); como lo afirma Nougé, el análisis clásico, la lógica interviene en su método, un procedimiento fundamentado en intenciones que describe en varias ocasiones. Se trata ante todo de crear «objetos turbadores». La subversión de las imágenes procede de su capacidad de «ocupar la consciencia humana hasta el punto de agotar el flujo monótono, hasta el punto de forzar la mente a inventar algo que le permita saltar más allá» (Nougé 1980, 239).

Se trata pues de sacar al espectador de su contexto cultural; en este sentido, la pintura deberá desbaratar su horizonte de espera ordinario - la facilidad a la cual está acostumbrado-, pero también sus esperas perceptivas, para provocar la interrupción del torbellino del pensamiento, «parar así el flujo de palabras y de fantasmas, la inmensa huida que la constituye normalmente» (Nougé 1980, 231), para fijar la conciencia sobre las imágenes hasta hacerla coincidir con ellas. Aquí es cuando el racionalista y el materialista ateo encajan con la mística meditativa cuando afirma que el espíritu, inmovilizado por el objeto, «rompe cualquier dique y desborda de repente en plena luz. Obliga al hombre a ver, a pensar, a sentir lo que no pensaba ni experimentar o querer jamás. Así se podría explicar la potencia de la pintura que no sea indigna. Aquí se puede hablar de "iluminación", de "revelación"» (Nougé 1980, 231). Existe pues en Nougé, una interacción entre el proceso de racionalización y la intuición, el primero encadenándose con la segunda para llevar al ser a intensificar su experiencia con el mundo. La visualización de un objeto es susceptible de provocar este estado trastornador. Para lograr esta meta, se trata de aislarlo de su contexto habitual, de sus lazos afectivos o usuales; es imprescindible que quede «separado por cualquier operación misteriosa del universo tupido al cual pertenece [...] extrañamente desligado » (Nougé 1980, 233). Poco importa la naturaleza del objeto, puede ser común, aunque los objetos de implicaciones afectivas pueden contener una mayor «potencia subversiva». ${ }^{15} \mathrm{El}$ aislamiento confiere una sensación de novedad, el carácter repentinamente enigmático, una

$15 \ll[\ldots]$ la potencia subversiva de un objeto aislado está en razón directa con la intensidad de las relaciones que guarda con nuestro cuerpo, con nuestro espíritu, con nosotros mismos» (Nougé 1980, 239). 
presencia ininteligible. Dicha abstracción del contexto procede de una metodología detallada por Nougé $(1980,240)$; evoca, por ejemplo, en los cuadros de Magritte, el cambio de escala (Les Valeurs personnelles, 1952) o de decorado (La Durée poignardée, 1938); una vez realizada la operación de aislamiento, un objeto será apto para «todas las "perversiones"» (Nougé 1980, 236) en su relación con otro objeto, desde «la simple vecindad» (La Bataille de l’Argonne; Le fils de l’homme, 1964), hasta «la fusión más íntima» (Les Amants, 1928) y «la transubstanciación...» (Nougé 1980, 236) (Le Modèle rouge, 1935; La Magienoire, 1945).

En esta perspectiva, la pintura de Magritte se acerca al Surrealismo bretoniano en cuanto a que se sirve «de la aproximación de dos realidades más o menos alejadas. Cuanto más lejanas y justas sean las relaciones de las dos realidades acercadas, más fuerte será la imagen, y poseerá más potencia emotiva y realidad poética» (Breton 1988, 324). Según Nougé, sin embargo, se requiere una intervención mínima; una coma en la escritura basta para cambiar el sentido de un texto, y en pintura «el juego de un solo trazo de tinta negra» (Nougé 1980, 241). Hay que añadir a la incidencia del objeto sustraído de su contexto, la atribución del título al cuadro que da un paso más en la desestabilización del espectador, con el cuestionamiento del enigma que plantea. Este desplazamiento de lo esperado crea el objeto «bouleversant»: «Lo maravilloso sólo existe para el alma tensa y paciente y para el ojo que se fija» (Nougé 1980, 247). Esta tensión buscada en la escritura y en la pintura, Nougé la aplica también en sus relaciones con los demás, porque para un surrealista -y cualquier artista de vanguardia- se trata primero de vivir y aplicar en lo cotidiano su propia visión poética para escaparse de la mediocridad y de la mezquindad de la vida material. Marcel Mariën se acuerda que Nougé «ponía todo el tiempo en práctica lo que había llamado, por otra parte, de manera general, la experiencia, la experiencia continua. Era la poesía en la vida cotidiana» (Mariën 1997, 39).

Los cálculos de Nougé que pretendían molestar las pequeñas costumbres no le gustaban a todo el mundo. Se le había atribuido un carácter difícil, pero Mariën subrayó que no era el caso. Nougé era destructor en un sentido positivo y había inventado la «mentira fértil» (Mariën 1997, 40), hasta tal punto de que su simple presencia creaba una tensión, la expectativa de un malentendido, una situación falsa, la mera sensación de algo inconfortable. Por ejemplo, siempre cedía su sitio a Magritte, que detestaba sentarse en una silla o un sillón calentado por otro-lo que Nougé sabía pertinazmente-o se había acostumbrado a abrazar a Mariën -lo que le molestaba bastante- y subía el sonido de la radio cuando uno no se enteraba de la conversación; el día anterior a su muerte, habló con Mariën de la historia de un amigo que acababa de tener un accidente y sólo habló de aquello, con alusiones de doble sentido, relacionadas con ambos contextos (Mariën 1997, 42-44). Cuando Mariën había empezado a transcribir sus ma- 
objetivo de su publicación, Nougé siempre se había mostrado conforme y no cambiaba ni una coma; sin embargo, un día se puso a corregir de manera inhabitual un texto que Mariën le había entregado; luego se dio cuenta de que este fragmento no era de Nougé sino de Jean de Boschère: Nougé había corregido el texto de otro autor, le gustaba crear malentendidos. Para él, no era el acuerdo sino el desacuerdo entre los hombres el que podía ser fecundo, dinámico, el que producía el movimiento de la creación (vid. Mariën 1997, 46-48).

\section{CONCLUSIÓN}

No se puede contemplar un movimiento literario en Bélgica, a finales del siglo XIX y principios del siglo XX, sin cuestionar su relación compleja con la institución literaria francesa. Hemos visto que el movimiento simbolista belga brilló en beneficio del florecimiento de instancias de legitimación originadas en Bélgica en la segunda mitad del siglo XIX, pero, a la vez, que este reconocimiento quedó también condicionado al grado de alteridad que presentaba: en este caso en atención a las fuentes de inspiración nórdicas, en los temas de las obras y en sus bases filosóficas, místicas y esotéricas.

Parece existir una filiación entre los intereses de Maeterlinck y los de André Breton, pero no es ahí donde los surrealistas belgas y franceses pudieran encontrarse. Todo lo contrario. En una lógica de tensión, de oposición entre ambos campos literarios, con vista también a un reconocimiento velado, la cabeza pensante del grupo de Bruselas, Paul Nougé, aplica preceptos inversos a los de Breton para afirmar numerosas diferencias metodológicas: dominación/ control frente a discreción/retirada; trabajo a partir de lo inconsciente versus cálculo/intervención lógica; originalidad afirmada/intervención mínima y rechazo de la originalidad. No obstante, se trata en ambos casos de llenar la vida de ella misma.

\section{REFERENCIAS BIBLIOGRÁFICAS}

ARON, P. (éd.) 1997: La Belgique artistique et littéraire. Une anthologie de langue française. 1848-1914. Bruxelles: Complexe.

ARON, P. 1993: «Préface» à Correspondance. Bruxelles: Didier Devillez Éditeur.

ARON, P. et SOUCY, P.-Y.1993: Les Revues littéraires belges de langue française de 1830 à nos jours. Bruxelles: Labor, coll. «Archives du futur».

ARTAUD, A. 1923: «Préface» de Maeterlinck, M., Douze chansons. Paris: Stock, 1923.

BAUDET, C. 1986: Grandeur et misère d'un éditeur belge: Henry Kistermaeckers (18511934). Bruxelles: Labor.

BIRON, M. 1991: «Le refus de l'oeuvre chez Paul Nougé», en Textyles, nº 8, pp.53-70. 
BIRON, M. 1994: La Modernité belge. Bruxelles: Labor, coll. «Archives du futur». BRETON, A. 1985: Manifestes du surréalisme. Paris: Gallimard, 1985. BREton, A. 1988: CEuvres complètes [1924]. Paris: Gallimard, 1988. DELAY, N. 2000: «Le premier symbole maeterlinckien», en Correspondance, 6, pp. 16-32.

DUbois, J. 2005: L’institution de la littérature [1978]. Bruxelles: Labor.

DURAND, P. et WINKIN, Y. 1996: Marché éditorial et démarches d'écrivains. Un état des lieux et des forces de l'édition littéraire en Communauté française de Belgique. Bruxelles: Service des Lettres-Direction générale de la Culture et de la Communication.

DURAND, P. et WINKIN, Y. 2000: «L'infrastructure éditoriale» en BERG, Ch. et HALEN, P., Littératures belges de langue française. Histoire et Perspectives (1830-2000). Bruxelles: Le Cri.

GORCEIX, P. (éd.) 1998: Fin de siècle et symbolisme en Belgique. Euvres poétiques. Bruxelles: Éditions Complexe.

GORCEIX, P. 1997: Maurice Maeterlinck. Le Symbolisme de la différence. Mont-de Marsan: Éd. InterUniversitaires.

KLINKENBERG, J.-M. 1981: «La production littéraire en Belgique francophone», en Littérature, 44, pp.33-50.

LACOUE-LABARThe, Ph. et NANCY, J.-L. 1978: L'absolu littéraire. Théorie de la littérature du Romantisme allemand. Paris: Seuil.

LARoche, D. 1991: «Le style Nougé», en Surréalismes de Belgique. Textyles, nº 8, pp.39-51.

MAETERLINCK, M. 1985: «Enquête sur l'évolution littéraire. (Jules Huret)» [1891], en Introduction à une psychologie des songes et autres écrits. 1886-1896. Bruxelles: Labor, coll. «Archives du futur».

MAeTERLINCK, M. 2008: Le Trésor des humbles [1896]. Paris: Grasset.

MARIËN, M. 1997: Tout reste à dire. Un entretien avec Christian Bussy. 1970. Bruxelles: Didier Devillez.

MICHEL, G. 1997: «Paul Nougé et les «lambeaux de langage». Quels procédés pour quels effets?» en SONCINI, A. (éd.) Paul Nougé : pourquoi pas un centenaire ? Actes du colloque de Rimini, 31 mars-2 avril 1995. Bologne, Clueb, pp. 201-233. Michel, G. 2011: Paul Nougé. La Poésie au cour de la révolution. Bruxelles: Peter Lang. NOUGÉ, P. 1980: Histoire de ne pas rire. Lausanne: L’Âge d'Homme.

Nougé, P. 1981: L'expérience continue. Lausanne: L’Âge d'homme.

Puelles, L. 2007: Lo posible. Fotografías de Paul Nougé. Murcia: Cendeac, coll. «Infraleves», $\mathrm{n}^{\circ} 7$.

Martine Renouprez es Profesora titular de Filología Francesa en la Universidad de Cádiz. 
